\title{
RESEARCH IN PROGRESS
}

\section{Academy of Ayurveda, Hanumanpet, Vijayawada - 520 003, Andhra Pradesh}

The Academy of Ayurveda, reports a spot test calls 'NAMBURI PHASED SPOT TEST', the utility of which has been fully explored as a general one, to identify Ayurvedic and Siddha Bhasmas and Sinduras. In this method, a drop of the solution of the Bhasma Sindura under examination is placed on whatman paper No.1 (impregnated with a suitable reagent and dried). As a reactants continue to react for a long time, the spot is examined for the specific colours and pattern produced within the first five minutes, then within the next 15 minutes and then afterwards within a considerable time lag. The special feature of this technique is, not only the colour developed during the reaction but also the pattern and display of the spot and its stability. For instance, Bhasmas from different Calcareous shells of marine origin viz, Coral (Pravala), Cowire (Varatika), Conch (Sankha), Pearl - Oyster - Shell (Sukti) and Pearl (Mukta) develop pink colour when their solutions are treated with turmeric paper (Prepared by impregnating whatman paper No.1 with an alcoholic extract of turmeric and dried). But in each case the pattern of pink colour and the periphery of the spot is different and characteristic or rather specific. Moreover, of these some initially - produced colour are stable and others fade away rapidly. This also forms the basis to distinguish the above group of bhasmaas from each other. Thus the source of the bhasmaas is specifically identified though they are chemically Calcium Oxide or Carbonate. In other words, this technique helps to identify these bhasmaas by their specific names as known in Ayurveda. Interestingly, even Bhasmas and Sinduras of Gold can be identified on the above turmeric paper by virtue of the purple spot developed on it.

This techniques goes a long way to lay scientific standards relevant to the concepts of Ayurveda and guards the qualities of Bhasmas and Sinduras.

\author{
Dr. N. Hanumantha Rao, \\ Director.
}

